\title{
ESTUDO DAS CONDIÇÕES MICROBIOLÓGICAS E TEORES DE NITRITO EM SALAMES PRODUZIDOS NO ALTO VALE DO RIO DO PEIXE - SANTA CATARINA, BRASIL
}

\author{
Araldi EZ , Moreira J** Mazurek L ${ }^{* * *}$, Araldi LZ ${ }^{* * * *}$, Ariotti AP ${ }^{* * * *}$, Soares FASM ${ }^{* * * * *}$
}

Resumo

A região Meio-Oeste de Santa Catarina merece destaque na produção de suínos pelos grandes frigoríficos instalados. A imigração italiana trouxe também para esta região pequenas indústrias beneficiadoras com o intuito de agregar valor e produzir produtos cárneos, como salames. Os pequenos frigoríficos processadores situados na região do Alto Vale do Rio do Peixe, não possuem laboratórios próprios para monitorar a qualidade das matérias-primas utilizadas na fabricação de salames nem mesmo do produto a ser destinado ao consumidor; por conta disso, as amostras são enviadas

\footnotetext{
“ Graduado em Engenharia de Alimentos pela Universidade do Oeste de Santa Catarina de Videira; edimar26araldi@gmail.com ${ }^{* *}$ Graduada em Biotecnologia Industrial pela Universidade do Oeste de Santa Catarina de Videira; jeh_moreira1605@hotmail.com

${ }^{* * *}$ Graduanda em Biotecnologia Industrial pela Universidade do Oeste de Santa Catarina de Videira; letimazurek@yahoocom.br

${ }^{* * * *}$ Graduado em Engenharia de Alimentos pela Universidade do Oeste de Santa Catarina de Videira; lenirzago@gmail.com

${ }^{* * * *}$ Pós-graduada em Acupuntura pelo Colégio Brasileiro de Estudos Sistêmicos; Pós-graduada em Obesidade pelo Instituto de Pesquisa, Capacitação e Especialização; Graduada em Nutrição pela Universidade do Vale do Itajaí; mestranda do Programa de Pós-graduação em Ciência e Biotecnologia da Universidade do Oeste de Santa Catarina; anapaula.ariotti@unoesc.edu.br

${ }_{* * * * * *}$ Doutora em Ciências Farmacêuticas pela Universidade de São Paulo; Mestre em Tecnologia Bioquímico-Farmacêutica pela Universidade de São Paulo; Professora do Programa de Pós-graduação em Ciência e Biotecnologia na Universidade do Oeste de Santa Catarina; Rua Paese, 198, Universitário, 89560-000, Videira, Santa Catarina, Brasil; fabiana.soares@unoesc.edu.br
} 
a laboratórios de terceiros onde se avalia o produto, comprovando sua qualidade e o cumprimento das exigências legais. Nesse contexto, o objetivo com este trabalho foi avaliar a qualidade microbiológica de salames produzidos por três empresas do Alto Vale do Rio do Peixe, bem como determinar os teores de nitritos e compará-los aos valores estabelecidos pela Legislação vigente no País. As análises foram executadas entre agosto e setembro de 2016 utilizando metodologia oficial determinada pelo Ministério da Agricultura, Pecuária e Abastecimento. Concluiu-se que todas as amostras atenderam aos padrões microbiológicos exigidos pela Legislação. Os resultados obtidos para as análises de nitrito demonstram que $100 \%$ das amostras das três marcas analisadas continham teores de nitritos dentro da Legislação vigente, ou seja, abaixo de $150 \mathrm{mg} / \mathrm{kg}$, o que prova que a produção de salames em pequenas agroindústrias desta região do Estado de Santa Catarina encontra-se em condições seguras de consumo.

Palavras-chave: Embutidos cárneos. Conservantes. Nitrito de sódio. Contaminação de alimentos. Padrões microbiológicos.

\title{
Study of microbiological conditions and nitrite content in salami produced at the region of Alto Vale do Rio do Peixe - Santa Catarina, Brazil
}

\begin{abstract}
The region of the Midwest of Santa Catarina deserves highlight in swine production by the large installed cold stores. The Italian immigration also brought to this region small industries in order to add value and produce meat products, such as salami. Small industrializers cold stores located in the region of Alto Vale do Rio do Peixe do not have their own laboratories to monitor neither the quality of the raw materials used in the manufacture of salami nor of the product to be sent to the consumer; because of that, the samples are sent to third laboratories where the product is evaluated, proving its quality and the compliance with legal requirements. In this context, the aim of this study was to evaluate the microbiological quality of salamis produced by three companies of the region of Alto Vale do Rio do Peixe, as well as determining the levels of nitrites and compare them to the values established by the current Legislation in the Country. The analyses were performed between August and September 2016 using official methodology determined by the Ministry of Agriculture, Livestock and Supply (MAPA). It was concluded that all the samples met the microbiological standards required by the Legislation. The results for nitrite analysis show that $100 \%$ of the samples of the three brands analyzed contained nitrite levels within the current Legislation, ie below $150 \mathrm{mg} / \mathrm{kg}$, what proves that the salami production in small agro-industries in this region of the State of Santa Catarina is in safe condition for consumption.

Keywords: Canned meat. Preservatives. Sodium nitrite. Food contamination. Microbiological standards.
\end{abstract}

\section{INTRODUÇÃO}

Segundo o relatório da Associação Brasileira de Proteína Animal, o Brasil destina 84,8\% da produção de carne suína para exportação e 15,2\% para industrialização, com uma produção de 3.643 
ton/ano, e tem como maior produtor o Estado de Santa Catarina, com 27,4\%. Segundo o autor, em 2010 o consumo per capita foi de 13,36 kg de carne suína por habitante. Por ser o maior produtor de carne suína, Santa Catarina comercializa para outros países não somente o que produz internamente, mas também a produção vinda de outros estados, como Rio Grande do Sul e Paraná, sendo que 52,7\% da produção passa pelo porto de Itajaí.

A região Meio-Oeste de Santa Catarina merece destaque na produção de suínos pelos grandes frigoríficos instalados, porém a imigração italiana para esta região forneceu pequenas indústrias beneficiadoras destas matérias-primas com o intuito de agregar valor e produzir produtos cárneos, como salames.

Segundo a Instrução Normativa n. 22, de 31 de julho de 2000, do Ministério da Agricultura, Pecuária e Abastecimento:

Entende-se por salame, o produto cárneo industrializado, elaborado exclusivamente a partir de carnes suínas, adicionado de toucinho, moído em granulometria variável, embutido em envoltório natural, curado, que sofre um processo rápido de fermentação, defumado e dessecado por tempo indicado pelo processo de fabricação.

A carne suína tem elevado valor nutricional, porém pode facilmente favorecer o desenvolvimento microbiano. Entre as bactérias tidas como fonte comum de contaminação tem-se Staphylococcus aureus, Salmonella sp., Clostridium sulfito redutores, bactérias entéricas como coliformes fecais e estreptococos fecais provenientes do intestino dos próprios animais.

Os coliformes são microrganismos gram-negativos em forma de bastonetes, aeróbios ou anaeróbios facultativos, não formadores de esporos e que fermentam a lactose com produção de ácido e gás quando incubados em temperatura de 35 a $37^{\circ} \mathrm{C}$ por 48 horas em meio sólido ou líquido. Essa definição é a mesma para o grupo de coliformes termotolerantes, porém estes são capazes de fermentar a lactose com produção de gás, em 24 horas, a uma temperatura de 44,5 a 45,5 ${ }^{\circ} \mathrm{C} .{ }^{7}$ Esses microrganismos também são denominados coliformes a $45^{\circ} \mathrm{C}$ ou coliformes termotolerantes.

Segundo Teixeira, a Salmonella sp está entre os patógenos mais problemáticos e a salmonelose é a enfermidade proveniente de carne e produtos cárneos que se apresenta com maior frequência em diversos países. Salames e linguiças podem ser facilmente responsáveis por surtos de salmonelose, visto que são consumidos crus ou malcozidos e comumente são expostos sem maiores cuidados de higiene e refrigeração.

Segundo autores pesquisados, a Salmonella sp. é um gênero da família Enterobactereaceae. São bastonetes gram-negativos, anaeróbios facultativos, que não produzem esporos, catalase positivos, oxidase negativos e que habitam o trato intestinal de homens e animais. São relativamente termosensíveis, podendo ser destruídas a $60^{\circ} \mathrm{C}$ por 15 minutos; a temperatura ótima de crescimento varia de 35 a $43^{\circ} \mathrm{C}$, mas podem crescer numa faixa de 7 a $47^{\circ} \mathrm{C}$; o $\mathrm{pH}$ ótimo varia entre 7 e 7,5, mas podem crescer em $\mathrm{pH}$ de 4,5 a 9,0 e requerem uma atividade de água (aw) mínima de 0,93. 
Os Staphylococcus aureus são bactérias gram-positivas, catalase positiva e se dividem em mais de um plano para formar agrupamento tridimensional de células em forma de cacho de uva. Produzem enterotoxinas estafilocócica que causam gastroenterite ou inflamação das mucosas gástricas ou intestinal. ${ }^{6}$

Os Staphylococcus aureus são capazes de se desenvolver em condições bastante variáveis. São mesófilos, com crescimento na faixa entre 7 e $47{ }^{\circ} \mathrm{C}$, visto que as enterotoxinas são produzidas em temperaturas de 10 a $46^{\circ} \mathrm{C}$; toleram altas concentrações de cloreto de sódio (10-20 \%) e também são resistentes aos nitratos e nitritos. Multiplicam-se em pH de 4,0 a 10, tendo desenvolvimento ótimo em valores próximos da neutralidade, como para a grande maioria das bactérias.

Os Clostridiuns sulfito redutores são bactérias de morfologia bacilar, gram-positivas, anaeróbias estritas, capazes de formar esporos e com atividade sulfito redutores fermentadores de lactose, com pH de crescimento ótimo em torno de 7,2, sendo o mínimo de 5,5 e o máximo 9,0; crescem em altas temperaturas, ótimas na faixa de 43 a $47^{\circ} \mathrm{C} .^{11}$

As bactérias mesófilas constituem um grupo capaz de se multiplicar entre 10 e $45^{\circ} \mathrm{C}$, sendo a temperatura ideal em torno de $30^{\circ} \mathrm{C}$. Esse grupo é importante porque inclui a maioria dos contaminantes dos alimentos de origem animal, podendo atingir altas contagens quando o alimento é mantido em temperatura ambiente.

O número de microrganismos aeróbios mesófilos encontrados em um alimento tem sido um dos indicadores microbiológicos da qualidade dos alimentos mais comumente utilizados, indicando se a limpeza, a desinfecção e o controle da temperatura durante os processos de tratamento industrial, transporte e armazenamento foram realizados de forma adequada. Essa determinação permite também obter informação sobre a alteração incipiente dos alimentos, sua provável vida útil e desvios na temperatura de refrigeração estabelecida.

A qualidade de salames pode ser verificada por intermédio de análises microbiológicas, as quais devem estar de acordo com os padrões estabelecidos pela Anvisa, por meio do Regulamento Técnico sobre Padrões Microbiológicos para Alimentos. ${ }^{14}$ A produção de salames envolve várias etapas de manipulação, aumentando, com isso, as possibilidades de contaminação por diversas espécies de microrganismos, patógenos ou deterioradores, comprometendo a qualidade deste alimento.

A utilização de sais de nitrito e nitrato em produtos cárneos é secular, e com a evolução das técnicas de conservação alimentar, tem crescido cada vez mais, pois além do melhoramento no aspecto de sabor e cor, esses sais têm ação preventiva na germinação e proliferação de esporos de algumas bactérias, além de serem antioxidantes, ou seja, aumentam o tempo de conservação do produto.

Há estudos sobre os danos que os nitritos podem ocasionar em nosso organismo; nesse intuito, a Legislação estabelece limite máximo de $150 \mathrm{mg} / \mathrm{kg}$, mas sabe-se que a adição de sais de nitritos causa toxicidade e está associada à formação de nitrosaminas, reconhecidas como substâncias potencialmente cancerígenas.

Os pequenos frigoríficos processadores situados na região do Alto Vale do Rio do Peixe não possuem laboratórios próprios para monitorar a qualidade das materias-primas utilizadas na fabri- 
cação nem do produto a ser destinado ao consumidor; por conta disso, as amostras são enviadas a laboratórios terceiros onde se avalia o produto, comprovando sua qualidade e o cumprimento das exigências legais. Nesse contexto, o presente trabalho foi desenvolvido com o objetivo de avaliar a qualidade microbiológica de salames produzidos por três empresas do Alto Vale do Rio do Peixe, bem como determinar os teores de nitritos e compará-los com os valores estabelecidos pela Legislação vigente no País.

\section{MATERIAIS E MÉTODOS}

\subsection{COLETA DE AMOSTRAS}

Foram selecionadas três marcas locais com inspeção estadual (SIE), localizadas nos municípios do Alto Vale do Rio do Peixe, no Estado de Santa Catarina. Dessas marcas, foram coletadas amostras de um mesmo lote entre os meses de agosto e setembro de 2016, sendo analisados três lotes de cada marca. As marcas foram identificadas com as letras A, B e C a fim de preservar sua identidade. As amostras foram adquiridas em supermercados da Cidade de Videira, Santa Catarina. A Tabela 1 traz as informações de lote, data de fabricação e validade dos lotes analisados.

\begin{tabular}{|c|c|c|c|c|}
\hline MARCA & & LOTE & FABRICAÇÃO & VALIDADE \\
\hline \multirow{3}{*}{ A } & 1 & 80 & $02 / 08 / 2016$ & $01 / 11 / 2016$ \\
\hline & 2 & 82 & $12 / 09 / 2016$ & $11 / 12 / 2016$ \\
\hline & 3 & 85 & $24 / 09 / 2016$ & $24 / 12 / 2016$ \\
\hline \multirow{3}{*}{ B } & 1 & 10816 & $01 / 08 / 2016$ & $01 / 11 / 2016$ \\
\hline & 2 & 120916 & $11 / 09 / 2016$ & $11 / 12 / 2016$ \\
\hline & 3 & 210916 & $21 / 09 / 2016$ & $21 / 12 / 2016$ \\
\hline \multirow{3}{*}{ C } & 1 & 33 & $01 / 08 / 2016$ & $01 / 10 / 2016$ \\
\hline & 2 & 35 & $16 / 09 / 2016$ & $16 / 12 / 2016$ \\
\hline & 3 & 40 & 20/09/2016 & $20 / 09 / 2016$ \\
\hline
\end{tabular}

Cada lote foi composto por três peças de salame de aproximadamente $300 \mathrm{~g}$, embutidas em envoltório natural e em formato ferradura. Priorizou-se a coleta de amostras com o menor tempo de vida de prateleira entre produção e análise, com prazo médio de sete dias após fabricação. Em relação ao tempo de validade, também observou-se que todas as empresas estipularam prazo de validade de 90 dias e todas as amostras estavam dentro do prazo de validade. As amostras foram mantidas em temperatura ambiente, acondicionadas em sacos plásticos de PEBD para serem isoladas umas das outras.

Todos os ensaios foram realizados em triplicata nos laboratórios de microbiologia e físico-químico da Unoesc de Videira. 


\subsection{ANÁLISES MICROBIOLÓGICAS}

\subsubsection{Preparo da amostra}

Cada amostra sofreu processo de assepsia com álcool 70\% para diminuir a carga microbiana externa, bem como bolores e leveduras, evitando, assim, que fosse contaminado seu interior durante o processo. De cada peça foram coletadas porções em toda sua extensão, garantindo maior abrangência na amostragem, e em triplicata, uniformizando ainda mais o lote. O procedimento de preparo das amostras para análise microbiológica foi realizado conforme metodologia descrita pelo Ministério da Agricultura Pecuária e Abastecimento (MAPA) ${ }^{14}$ e recomendada para controle de produtos de origem animal e água.

Foram diluídas em água peptonada 0,1\%, acondicionadas em sacos estéreis e homogeneizadas em stomacher (HOMOGENIUS, Brasil) por 30 segundos, executando-se diluições subsequentes até a concentração desejada. Como indicativo de condição higiênico-sanitária de processamento desse embutido pelas empresas avaliadas, foi realizada a contagem de coliformes totais, coliformes termotolerantes a $45^{\circ} \mathrm{C}$, Staphilococcus aureus, Clostridium sulfito redutor e Bactérias mesófilas, além de pesquisa de Salmonella sp.

\subsubsection{Contagem de coliformes totais e coliformes termotolerantes}

A contagem de coliformes totais e coliformes termotolerantes foi realizada em Placas PetrifilmTM EC (3M Company, St. Paul, MN, EUA); inoculou-se com alíquotas de 1,0 ml das diferentes diluições, seguindo as instruções do fabricante. Após incubação das placas a $35 \pm 1{ }^{\circ} \mathrm{C}$ por 24 e 48 horas, colônias de coliformes que crescem na Placa Petrifilm produzem ácido, fazendo com que o indicador de $\mathrm{pH}$ torne a cor do gel vermelha mais escura. O gás retido ao redor das colônias vermelhas de coliformes indica coliformes totais confirmados. Para coliformes termotolerantes, a maioria dos microrganismos termotolerantes (cerca de 97\%) produz beta-glicuronidase na qual se forma um precipitado azul associado à colônia. $\mathrm{O}$ filme superior retém o gás formado pelos coliformes totais e termotolerantes que são fermentadores de lactose. Cerca de 95\% dos termotolerantes produzem gás, o que é indicado pelas colônias azuis a vermelho-azuladas. O resultado foi obtido pela contagem das colônias e expresso em UFC/g.

\subsubsection{Contagem de Staphylococcus aureus coagulase positiva}

A contagem de Staphylococcus aureus coagulase positiva foi realizada em triplicata, em que $100 \mathrm{uL}$ da amostra foram semeados em ágar Baird- Parker (DIFCO/França) e as placas foram incubadas a $36 \pm 1{ }^{\circ} \mathrm{C}$ por 24 a 48 horas. Foram selecionadas as placas que continham entre 15 e 150 colônias, contadas as colônias típicas (negras brilhantes rodeadas por um halo claro) e repicadas de três a cinco colônias em placa com caldo BHI (Infuso Cérebro Coração (OXOID, Inglaterra) incubando a 
$36 \pm 1^{\circ} \mathrm{C}$ por 48 horas. Para a identificação foi realizada prova da coagulase pela qual se verificou se o micro-organismo possui a coagulase (ou fator aglutinante) livre e ligada, que, reagindo com um fator plasmático, forma um complexo que atua no fibrinogênio do plasma, formando a fibrina e um coágulo inteiro ou parcial dentro do tubo.

\subsubsection{Contagem de Clostridium sulfito redutores}

A contagem foi realizada em triplicata em ágar SPS (Sulfito Polimixina Sulfadiazina (DIFCO, França), por meio da técnica de pour-plate de sobrecamada. As placas foram incubadas em anaerobiose a $36 \pm 1^{\circ} \mathrm{C}$ por 24 horas. As colônias possuem coloração negra e tamanho de 1 a $3 \mathrm{~mm}$ em razão da reação de redução de sulfito a sulfeto, que reage com citrato de amônio e ferro III, formando um precipitado negro.

\subsubsection{Pesquisa de Salmonella sp.}

Para a pesquisa de Salmonella sp., as amostras foram incubadas após serem homogeneizadas a $36 \pm 1{ }^{\circ} \mathrm{C}$ por 18 a 24 horas. Posteriormente, foram inoculados, respectivamente, $1 \mathrm{ml}$ dessa amostra em tubo contendo caldo tetrationato (MERCK/Alemanha) e 0,1 ml em caldo Rappaport-Vassiliadis (OXOID CM 866). Estes foram incubados a $41 \pm 1{ }^{\circ} \mathrm{C}$ por 24 a 30 horas. Em seguida, estas amostras foram estriadas separadamente em Ágar Salmonella Shigella/Ágar SS (DIFCO, França) e Xilose Lisina Desoxicolato/Ágar XLD (MERCK/Alemanha) e incubadas a $36 \pm 1{ }^{\circ} \mathrm{C}$ por 18 a 24 horas. Em Ágar SS as características da colônia de salmonella sp. e outros microrganismos não fermentadores de lactose podem produzir colônias opacas, translúcidas ou transparentes (com ou sem o centro preto). Em Ágar XLD as colônias possuem como característica metabolizar tiossulfato para produzir sulfureto de hidrogênio, o que leva à formação de colônias com centros pretos e permite que eles sejam diferenciados. Os testes bioquímicos foram realizados nas colônias características e foram expressos em presença ou ausência de Salmonella sp. em 25 g.

Para identificação de positividade da Salmonella foi utilizado kit pronto de identificação da empresa Laborclin (EUA) produtos para laboratórios lote 40120117, o qual utiliza cinco meios de cultura que fornecem provas bioquímicas associadas à leitura da fermentação da lactose, permitindo uma identificação segura da bactéria analisada. ${ }^{17}$

\subsubsection{Contagem de total de mesófilos}

Para a pesquisa de microrganismos mesófilos, a técnica tem por base a semeadura da amostra ou de suas diluições em ágar padrão para contagem, seguida de incubação em temperatura de $36 \pm 1^{\circ} \mathrm{C}$ por 48 horas. A partir da diluição inicial chegou-se à diluição $10^{-4}$ e inoculou-se $0,1 \mathrm{ml}$. Em seguida foi semeado adequadamente no Ágar Contagem Total (DIFCO, França), utilizando uma alça de Drigalsky, e deixou-se solidificar em superfície plana. 


\subsection{ANÁLISES FÍSICO-QUÍMICAS}

\subsubsection{Preparo da amostra}

Para a análise físico-química de nitritos, as amostras foram trituradas em triturador industrial (MONTE CASTELO, Brasil) da Universidade do Oeste de Santa Catarina (Unoesc) seguindo para determinação dos parâmetros físico-químicos. Em cada etapa as amostras foram analisadas pela

metodologia determinada pelo Ministério da Agricultura, Pecuária e Abastecimento, ${ }^{18}$ seguindo IT POA 030- Determinação de Nitrito em Produtos de Origem Animal por Espectrofotometria UV/Vis.

\subsubsection{Análise de nitrito}

Para análise de nitritos foram utilizados como reagentes: Tetraborato de Sódio decahidratado Na${ }_{2} \mathrm{~B}_{4} \mathrm{O}_{7} 10 \mathrm{H}_{2} \mathrm{O}$ (BORAX, Brasil), Ferrocianeto de Potássio trihidratado K4[Fe(CN)6].3H2O (DINAMICA, Brasil), Acetato de Zinco dihidratado ((CH3COO)2Zn.2H2O) (PROQUIMIOS, Brasil), Ácido Clorídrico $\mathrm{HCl}$ (HEXIS), Cloreto de Alfa-naftiletilenodiamina C12H16Cl2N2 (SIGMA-ALDRICH, Suiça), Sulfanilamida C6H8N2 O2S(HEXIS, Brasil) e Nitrito de Prata AgNO2 (PROLAB, Brasil), todos em grau analítico.

\subsubsection{Curva padrão ou curva de referência}

Para a curva padrão foram pipetadas alíquotas de $0,5,10,20,30,40$ e $45 \mathrm{ml}$ de solução padrão de trabalho de nitrito de sódio $10 \mu \mathrm{g} / \mathrm{ml}$ para balões volumétricos de $50 \mathrm{ml}$. Foram adicionados em cada balão $5 \mathrm{ml}$ de reagente sulfanilamida. Misturou-se, e após 5 minutos, foram adicionados $3 \mathrm{ml}$ de reagente NED em cada balão. Em seguida, foi completado o volume com água destilada e foi homogeneizado. A mistura foi deixada em repouso por 15 minutos e determinou-se em espectrofotômetro (PROANALISES) a 540 nm contra o branco de reagentes. Com os valores de absorbância foi calculada a curva de referência ou curva padrão com as concentrações de nitrito de sódio, obtendo-se as seguintes absorbâncias: 0,0. 0,036. 0,058. 0,135. 0,254. $0,350.0,388 \mu \mathrm{g} / \mathrm{ml}$. O critério de aceitação desta curva foi o valor $\mathrm{R}^{2}$ maior que 0,90 , conforme o Inmetro.

\subsubsection{Determinação espectrofotométrica do íon nitrito}

Foram pesados na balança analítica $10 \mathrm{~g}$ de amostra de salame triturada e homogeneizada em um balão volumétrico de $250 \mathrm{ml}$. Foram adicionados $5 \mathrm{ml}$ de solução tetraborato de sódio. Com um bastão de vidro, misturou-se e acrescentou-se $50 \mathrm{ml}$ de água quente a $80{ }^{\circ} \mathrm{C}$. O béquer com a amostra foi levado para o banho-maria por 15 minutos, agitando frequentemente e intensamente. Da mesma forma procedeu-se com a solução branca, sem o analito. Com ajuda do bastão de vidro e um funil, foi transferido quantitativamente o conteúdo para o balão volumétrico de $200 \mathrm{ml}$. Depois foi lavado o béquer com $50 \mathrm{ml}$ de água; foi deixado esfriar e adicionou-se mais $5 \mathrm{ml}$ de solução ferrocianeto de potássio e $5 \mathrm{ml}$ de solução de acetato de zinco. Foi agitado e completou- se o volume com água destila- 
da. Foi agitado novamente vigorosamente e deixado em repouso por mais 15 minutos (agitando constantemente). Posteriormente, foi filtrado em papel qualitativo para um frasco erlenmeyer de $250 \mathrm{ml}$.

Foram pipetados $10 \mathrm{ml}$ das amostras e do branco para as provetas de $50 \mathrm{ml}$ e foram adicionados 5 $\mathrm{ml}$ de reagente sulfanilamida. Aguardou-se cinco minutos e adicionou-se $3 \mathrm{ml}$ de reagente NED. Completou-se o volume com água, foi homogeneizado e deixado em repouso por mais 15 minutos. Fez-se a leitura no aparelho de espectrofotômetro a $540 \mathrm{~nm}$. O valor obtido de absorbância no espectrofotômetro foi aplicado na fórmula da curva de referência ou curva padrão. Todas as análises foram realizadas em duplicata.

\subsection{ANÁLISE ESTATÍSTICA}

Os valores obtidos na análise físico-química realizada nos embutidos foram submetidos a cálculo de média e análise de variância, utilizando função específica do Programa Excel da Microsoft Corporation, e ao teste de Tukey para comparação de médias com probabilidade de abrangência de 95\%.

\section{RESULTADOS E DISCUSSÃO}

\subsection{AVALIAÇÃO DOS PADRÕES MICROBIOLÓGICOS}

A Tabela 2 apresenta os resultados microbiológicos dos salames produzidos por pequenas empresas do Alto Vale do Rio do Peixe no período de agosto a setembro de 2016. Todas as amostras analisadas estão dentro dos limites aceitáveis de acordo com a Resolução RDC n. 12, de janeiro de 2001. 
Tabela 2 - Resultados das análises microbiológicas realizadas nos salames produzidos por pequenas empresas do Alto Vale do Rio do Peixe no período de agosto a setembro de 2016

\begin{tabular}{|c|c|c|c|c|c|c|c|c|c|c|}
\hline \multirow{2}{*}{${\mathrm{M} . O 1^{\dagger}}^{\dagger}$} & \multirow{2}{*}{$\begin{array}{l}\text { RDC } \\
\text { n. } 12\end{array}$} & \multicolumn{3}{|c|}{ A } & \multicolumn{3}{|c|}{ B } & \multicolumn{3}{|c|}{$\mathrm{C}$} \\
\hline & & 1 & 2 & 3 & 1 & 2 & 3 & 1 & 2 & 3 \\
\hline $\begin{array}{l}\text { Salmo- } \\
\text { nella }\end{array}$ & $25 \mathrm{~g} 2^{\ddagger}$ & $\mathrm{A} 25 \mathrm{~g}^{\ddagger}$ & $\mathrm{A} 25 \mathrm{~g}^{\ddagger}$ & $\mathrm{A} 25 \mathrm{~g}^{\ddagger}$ & $\mathrm{A} 25 \mathrm{~g}^{\ddagger}$ & $\mathrm{A} 25 \mathrm{~g}^{\ddagger}$ & $\mathrm{A} 25 \mathrm{~g}^{\ddagger}$ & $\begin{array}{r}\mathrm{A} 25 \\
\mathrm{gr}^{ \pm}\end{array}$ & A25 $\mathrm{gr}^{\ddagger}$ & A25 $\mathrm{gr}^{*}$ \\
\hline S.aureus ${ }^{\dagger}$ & $5 \times 10^{3}$ & $1,3 \times 10^{3}$ & $1,22 \times 10^{3}$ & $1,1 \times 10^{3}$ & $1,9 \times 10^{3}$ & $2,01 \times 10^{3}$ & $1,85 \times 10^{3}$ & $2,3 \times 10^{3}$ & $1,84 \times 10^{3}$ & $3,12 \times 10^{3}$ \\
\hline $\begin{array}{l}\text { C. Sulfito } \\
\text { Reduto- } \\
\text { res }^{\dagger}\end{array}$ & $3 \times 10^{3}$ & $<10$ & $<10$ & $<10$ & $<10$ & $<10$ & $<10$ & $<10$ & $<10$ & $<10$ \\
\hline $\begin{array}{l}\text { Coli- } \\
\text { formes } \\
\text { Totais }^{\dagger}\end{array}$ & $10^{3}$ & $399 /$ & $445 /$ & $258 /$ & $265 /$ & $655 /$ & $267 /$ & $580 /$ & $112 /$ & $256 /$ \\
\hline $\begin{array}{l}\text { C. Ter- } \\
\text { motole- } \\
\text { rantes } \dagger\end{array}$ & 103 & $<100$ & $<100$ & $<100$ & $<100$ & $<100$ & $<100$ & $<100$ & $<100$ & $<100$ \\
\hline $\begin{array}{c}\text { Mesófi- } \\
\text { los } \dagger\end{array}$ & - & $9,4 \times 10^{5}$ & $5,76 \times 10^{6}$ & $6,14 \times 10^{6}$ & $2,09 \times 10^{7}$ & $5,63 \times 10^{6}$ & $4,87 \times 10^{7}$ & $5,4 \times 10^{7}$ & $5,1 \times 10^{7}$ & $2,9 \times 10^{7}$ \\
\hline
\end{tabular}

Fonte: Brasil. ${ }^{8}$

Em relação ao parâmetro de Contagem de Staphylococcus aureus, as amostras de salame das

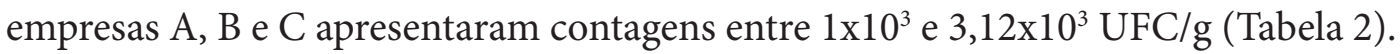

O micro-organismo Staphylococcus coagulase positiva geralmente é proveniente da matéria-prima e da manipulação por pessoas portadoras do microrganismo. Quando o alimento contaminado é ingerido, pode ocasionar sintomas como vômitos e dores abdominais. ${ }^{20}$ Ressalta-se que essa contagem de Staphylococcus aureus é considerada insuficiente para a produção de enterotoxina, estando dentro dos limites estabelecidos.

Comparando o resultado encontrado com outros trabalhos, observa-se que Teixeira ${ }^{9}$ avaliou a qualidade microbiológica e os padrões físico-químicos de salame colonial na região de Criciúma, SC, e observou que, das cinco amostras coletadas, somente três estavam dentro dos padrões estabelecidos pela RDC n. 12 de 2001, sendo estas monitoradas por inspeção municipal e estadual. As demais eram de produção familiar e não passavam por nenhum tipo de inspeção.

Segundo autores pesquisados, ${ }^{21}$ avaliou-se a qualidade e identidade de embutidos produzidos no Baixo Vale do Rio do Peixe, Santa Catarina, observando-se que um lote de embutidos proveniente de um estabelecimento apresentou condições sanitárias insatisfatórias quanto a S. aureus.

As amostras provenientes dos salames produzidos no Alto Vale do Rio do Peixe não apresentaram contagem para os coliformes termotolerantes, obtendo-se valores menores que $100 \mathrm{UFC} / \mathrm{g}$, demonstrando o quanto o processo de higiene e boas práticas de fabricação está sendo seguido.

É importante destacar que, quanto aos coliformes termotolerantes, estes servem como indicador higiênico-sanitário e, quando em níveis inadequados, podem causar danos à saúde do con-

† Unidade de medida expressa em UFC.g-1

* A $25 \mathrm{~g}=$ Ausência em $25 \mathrm{~g}$. 
sumidor, como diarreia, vômitos, febre e dor abdominal. Estão presentes exclusivamente no trato intestinal.

Autores ${ }^{10}$ realizaram um estudo no Rio Grande do Sul com 13 amostras de salames, o qual revelou a presença de coliformes termotolerantes em $50 \%$ das amostras.

As amostras das empresas A, B e C submetidas à pesquisa de Salmonella sp. apresentaram resultado negativo para o microrganismo. A Salmonella está presente na maioria dos alimentos de origem animal como carnes e derivados, sendo oriunda de diversas fontes de contaminação, principalmente de origem fecal direta. Pequenas quantidades de Salmonella podem causar enfermidades, e é importante garantir sua ausência nos alimentos prontos para comer. Cuidados na obtenção da matéria-prima e nas condições de higiene e manipulação são indispensáveis para se evitar a presença deste microrganismo em salames.

Durante o estudo de Zocchi, ${ }^{23}$ foram encontradas duas amostras de salames produzidos e comercializados na região Oeste do Paraná contaminadas com Salmonella; na oportunidade 34 amostras foram estudadas.

Em outro estudo, autores ${ }^{21}$ avaliaram a qualidade e identidade de embutidos produzidos no Baixo Vale do Rio do Peixe e encontraram resultados semelhantes, sem a detecção da presença de Salmonella sp. Nos resultados de pesquisa de Clostridium sp, nas amostras das três empresas (A, B e C) não se evidenciou crescimento desse microrganismo em nenhuma das etapas, comprovando a eficácia dos nitritos como agente bactericida, já que previnem a germinação de esporos de Clostridium sp. ${ }^{12}$

Um estudo ${ }^{24}$ em estudo higiênico-sanitário realizado em salames demonstrou valores menores que $10 \mathrm{UFC/g}$, portanto, dentro dos limites estabelecidos pela Legislação Federal. ${ }^{8}$ Quanto às análises de microrganismos mesófilos, não há um padrão máximo permitido pela Legislação. Os mesófilos se multiplicam em uma faixa de temperatura entre 20 e $45^{\circ} \mathrm{C}$.

As amostras dos salames apresentaram contagem entre $9,4 \times 10^{5}$ e 5,4x107 UFC/g. Estes microrganismos podem ser deteriorantes, prejudicando o produto acabado e diminuindo a prazo de validade, e também podem ser benéficos em razão das bactérias lácticas que ajudam na fermentação e redução do $\mathrm{pH}$.

Em um estudo semelhante, a análise microbiológica de salames produzidos no Vale do Taquari, RS, detectou que inicialmente a contagem era alta, e com a maturação do produto, foram detectados números inferiores aos descobertos inicialmente em quantidade de microrganismos.

\subsection{AVALIAÇÃO DOS PADRÕES FÍSICO-QUÍMICOS}

Os resultados obtidos para as diferentes marcas analisadas constam na Tabela 3, na qual são expressos os resultados para os nitritos $\left(\mathrm{mg} / \mathrm{kg}^{-1}\right)$ em cada marca analisada. 
Tabela 3 - Resultados dos teores de nitrito presente nas marcas A, B e C nos salames produzidos por pequenas empresas do Alto Vale do Rio do Peixe no período de agosto a setembro de $2016^{\S}$

\begin{tabular}{|c|c|c|c|c|c|c|c|}
\hline Marca/período & & altado & & $\begin{array}{c}\text { Média } \\
\text { lotes }\end{array}$ & $\begin{array}{l}\text { Desvio } \\
\text { padrão }\end{array}$ & $\begin{array}{l}\text { Média } \\
\text { marcas }\end{array}$ & $\begin{array}{l}\text { Desvio } \\
\text { padrão }\end{array}$ \\
\hline A1 & 13,77 & 13,77 & 12,65 & $13,40^{\mathrm{a}}$ & 0,65 & \multirow{3}{*}{$12,76^{\mathrm{A}}$} & \multirow{3}{*}{1,08} \\
\hline A2 & 10,97 & 12,09 & 11,53 & $11,53^{\mathrm{b}}$ & 0,56 & & \\
\hline A3 & 13,77 & 13,77 & 12,65 & $13,40^{\mathrm{a}}$ & 0,65 & & \\
\hline $\mathrm{B} 1$ & 10,41 & 12,65 & 12,09 & $11,72^{\mathrm{a}}$ & 1,17 & \multirow{3}{*}{$17,26^{\mathrm{A}}$} & \multirow{3}{*}{5,51} \\
\hline $\mathrm{B} 2$ & 23,86 & 22,18 & 22,18 & $22,74^{\mathrm{b}}$ & 0,97 & & \\
\hline B3 & 16,01 & 18,26 & 17,70 & $17,32^{\mathrm{c}}$ & 1,17 & & \\
\hline $\mathrm{C} 1$ & 10,41 & 14,33 & 13,77 & $12,84^{\mathrm{a}}$ & 2,12 & \multirow{3}{*}{$15,58^{\mathrm{A}}$} & \multirow{3}{*}{3,53} \\
\hline $\mathrm{C} 2$ & 18,82 & 20,50 & 19,38 & $19,56^{\mathrm{b}}$ & 0,86 & & \\
\hline $\mathrm{C} 3$ & 13,77 & 14,33 & 14,89 & $14,33^{\mathrm{a}}$ & 0,56 & & \\
\hline
\end{tabular}

Durante o período de estudo, constatou-se uma variância estatística significativa no período 2 para as marcas A e C. Neste período, os lotes analisados apresentaram teores de nitrito diferentes que nos meses 1 e 3. Isso representa uma falha no processo produtivo.

Em estudo semelhante, Perufo e Hoehne ${ }^{27}$ analisaram os teores de sais de cura em salames na serra do Rio Grande do Sul onde as agroindústrias familiares seguiam as determinações da Legislação quanto à dosagem de nitratos e nitritos em cinco amostras. Das amostras avaliadas, quatro tiveram resultados de 5 ppm, e uma apresentou resultado de 81,10 ppm, demonstrando que a Legislação estava sendo seguida.

Em uma análise geral, pode-se observar que os resultados referentes ao valor residual de nitrito de sódio diferem consideravelmente dos dados apresentados por Rosa e Degaspari, ${ }^{28}$ que encontraram valores entre 54,76 e $66,45 \mathrm{mg} \cdot \mathrm{Kg}^{-1}$ em salames tipo italiano.

Entre as marcas pesquisadas, a marca B apresentou maior variância entre os lotes. Em cada lote adquirido e analisado, resultados muito diferentes foram encontrados, o que demonstra um ineficiente controle de qualidade do processo produtivo. Grandes variações como estas podem representar prejuízos à empresa em razão do uso incorreto dos conservantes e agentes de cura. $\mathrm{O}$ uso inadequado desses produtos pode acarretar um uso abusivo, colocando em risco a saúde de quem o consome em longo prazo, mas, por outro lado, seu uso em baixa concentração pode não garantir a estabilidade microbiológica do produto, afetando a saúde do consumidor em curto prazo.

Em uma comparação entre as médias de todas as marcas durante o período analisado, comprovou-se estatisticamente, com uma abrangência de $95 \%$ dos dados, que não há diferença significativa entre as marcas. Apesar das diferenças entre os lotes, no geral, as marcas apresentam comportamento e produtos com características semelhantes no que se refere ao teor de nitrito encontrado.

\footnotetext{
$\S$ Amostras com letras iguais não apresentam diferença estatística significativa entre si. Amostras com letras minúsculas diferentes apresentam diferença estatística significativa entre si.
} 


\section{CONCLUSÕES}

Os resultados microbiológicos obtidos para todas as amostras de salames produzidos pelas marcas analisadas apresentaram-se dentro dos padrões estabelecidos pela Resolução RDC n. 12, de 2 de janeiro de 2001, da Agência Nacional de Vigilância Sanitária (Anvisa) ${ }^{7}$. Conclui-se que a produção artesanal de salames na região do Alto Vale do Rio do Peixe, Estado de Santa Catarina, encontrava-se em condições satisfatórias de consumo em relação aos parâmetros analisados e para os lotes em questão.

A pesquisa revelou que os teores de nitritos encontrados nas amostras foram mais baixos que os esperados, porém dentro da legislação, já que esta não estabelece um teor mínimo para esse analito, o que demonstra a preocupação em atender à Legislação. Supõe-se que esteja sendo feita uma baixa dosagem do teor de nitrito nas formulações e que este esteja sendo consumido rapidamente no processo de cura, ou que até mesmo esteja sendo usado um sal de cura de qualidade inferior no qual os valores de nitrito de sódio residual não chegam a níveis de estabilizar o produto microbiologicamente. Porém, como a Legislação não prevê um limite mínimo, considera-se que as amostras estão dentro dos limites aceitáveis. Assim, mesmo estando os níveis de nitrito de sódio em menor concentração, as marcas analisadas mantiveram-se em níveis microbiológicos dentro dos padrões estabelecidos, não oferecendo risco ao consumidor.

\section{REFERÊNCIAS}

1. Associação Brasileira da Proteína Animal. Relatório Anual de Atividades 2014 [Internet]. São Paulo; 2015 [acesso em 2016 out 22]. Disponível em: http://abpa-br.com.br/files/publicacoes/ c59411a243d6dab1da8e605be58348ac.pdf

2. Gervasio EW. Carne Suína: fatores determinantes para o consumo [Trabalho de Conclusão de Curso] [Internet]. Curitiba: Universidade Federal do Paraná; 2012. [acesso em 2017 mar 18]. Disponível em: http://acervodigital.ufpr.br/bitstream/handle/1884/38967/R\%20-\%20E\%20-\%20 EDMAR\%20WARDENSK\%20GERVASIO.pdf?sequence=1

3. Suinocultura Industrial [homepage na Internet]. Em Santa Catarina, exportações de carne suína atingem maior índice da última década [acesso em 2017 mar 24]. Disponível em: http://www. suinoculturaindustrial.com.br/imprensa/em-santa-catarina-exportacoes-de-carne-suina-atingem-maior-indice-da-ultima/20170123-155938-J394

4. Marcondes T, Mior LC, Reiter JMV, Mondardo M. Os empreendimentos de agregação de valor e as redes de cooperação da agricultura familiar de Santa Catarina. Florianópolis: Epagri, 2012. 37 p. [Epagri. Documentos, 238]. 
5. Brasil. Ministério da Agricultura, Pecuária e Abastecimento. Secretaria de Defesa Agropecuária. Instrução normativa n. 22, de 31 de julho de 2000.

6. Batista LR, Carvalho EP. Microbiologia da Segurança de Alimentos [monografia]. Lavras: Universidade Federal de Lavras; 2011.

7. Carvalho IT. Microbiologia dos Alimentos [Internet]. Recife: EDUFRPE; 2010. [acesso em 2016 out 22]. Disponível em: http://pt.slideshare.net/AdrianaSantosSilva1/microbiologia-dos-alimentos-28041391

8. Brasil. Ministério da Saúde. Agência Nacional de Vigilância Sanitária. Resolução RDC n. 12, de 02 de janeiro de 2001. Regulamento técnico sobre padrões microbiológicos para alimentos.

9. Teixeira EB. Qualidade microbiológica e padrões físico-químicos de salame colonial na região de Criciúma/SC [monografia]. Lavras: Universidade Federal de Lavras; 2013.

10. Ritter R, Santos D, Agostini FS, Carboni AN, Bergmann GP. Microbiologia contaminante e patogênica de linguiça (salame) colonial, analisada em quatro períodos distintos. Hig Aliment. 2003; 17(113): 60-6.

11. Silva N, Junqueira VCA, Silveira NFA. Manual de métodos de análise microbiológica de alimentos. $2^{\text {a }}$ ed. São Paulo: Livraria Varela; 2001. 317 p.

12. Jay MJ. Microbiologia de Alimentos, 6a ed. Porto Alegre: Artmed; 2005.

13. Silva MC. Avaliação da qualidade microbiológica de alimentos com a utilização de metodologias convencionais e do sistema SimPlate [dissertação]. São Paulo: Universidade de São Paulo, Escola Superior de Agricultura Luiz de Queiroz; 2012.

14. Brasil, Ministério da Agricultura Pecuária e Abastecimento. Secretaria da Defesa Agropecuária. Instrução Normativa n. 62, de 26 de agosto de 2003. Oficializa os métodos analíticos oficiais para Análises Microbiológicas para Controle de Produtos de Origem Animal e Água. Diário Oficial da União. 2003 set. 18. 
15. Martins OA, Graner CAF. Determinações espectrofotométricas dos íons nitrito e nitrato em sais de cura. PUBVET 2008. Londrina; 2(18); 129-56

16. Stieven A, Souza CFV. Variação das concentrações de nitrato e nitrito em linguiça frescal, adicionadas de diferentes concentrações de eritorbato de sódio. Hig Aliment. 2012; 26(208/209): 180-6.

17. Laborclin produtos para laboratório [Internet]. [acesso em 2016 out 12]. Disponível em: http:// www.laborclin.com.br/produto.asp?id=510918

18. Brasil. Ministério da Agricultura Pecuária e Abastecimento. Secretaria de Defesa Agropecuária/ das. Coordenação Geral de Apoio Laboratorial/CGAL. Laboratório Nacional Agropecuário em Goiás/Lanagro-GO. Instrução de Trabalho. Determinação de nitrito em produtos de origem animal por espectrofotometria UV/Vis. 2011.

19. Instituto Nacional de Metrologia, Normalização e Qualidade Industrial (INMETRO). Orientações sobre Validação de Métodos de Ensaios Químicos, DOQ-CGCRE-008, 2003.

20. Franco BDGM, Landgraf M. Microbiologia dos Alimentos. São Paulo: Atheneu; 2002.

21. D’Agostini PF, Campana P, Degenhardt R. Qualidade e Identidade de Embutidos Produzidos no Baixo Vale do Rio do Peixe, Santa Catarina - Brasil 2009.

22. Bezerra MVP, Abrantes MR, Silvestre MKS, Sousa ES, Rocha MOC, Faustino JG et al. Avaliação microbiológica e físico química de linguiça toscana no município de Mossoró, RN. Arq Inst Biol. 2012; 79(2): 297-300.

23. Zocche F, Barcellos CV, Bersot SL. Microrganismos Indicadores e salmonella sp. em salames produzidos e comercializados na região oeste do Paraná. Universidade Federal do Pampa, 2011.

24. Hoffmann FL, Garcia-Cruz CH, Vinturim TM. Estudo higiênico-sanitário preliminar de amostras de salame. Hig Aliment. 1997; 11(47): 42-4. 
25. Maieski LM. Os Principais microrganismos que afetam a qualidade do leite [Internet]. Porto Alegre; 2011. [acesso em 2016 out 17]. Disponível em https://www.lume.ufrgs.br/bitstream/handle/10183/49725/000851317.pdf?sequence $=1$

26. Noschang MKM, Lehn ND. Salvatori, U, R. Análise microbiológica de lingüiças colonias produzidas no Vale do Taquari - RS. [acesso em 2016 out 10]. Disponível em: http://www.pucrs.br/ research/salao/2006VIISalaoIC/Arquivos2006/CienciasExatasedaTerra/36396\%20-\%20MICHELE\%20KOCH.pdf

27. Perufo BN, Hoehne L. Análise de Sais de Cura em Salames Tipo Colonial Comercializados na Serra do Rio Grande Do Sul. Revista Destaques Acadêmicos 2015; 7(4): 193-201.

28. Rosa TAM, Degaspari CH. Determinação quantitativa de nitrato e nitrito em salames tipo italianos comercializados na região de Colombo - Paraná. Revista Visão Acadêmica 2013; 14(4): 73-83.

Data da submissão: 15 de dezembro de 2016 Avaliado em: 15 de dezembro de 2016 (AVALIADOR A) Avaliado em: 15 de dezembro de 2016 (AVALIADOR B) Aceito em: 15 de dezembro de 2016 